\title{
Evaluation of Sugar Types in Selected Brands of Commercial Fruit Juice in Osun State, Nigeria
}

\author{
Adewale Akanni Tella Taleat, Florence AlabaAkanfe and Bolatito Olaitan Adeniyi \\ Science Laboratory Technology Department, \\ The Federal Polytechnic, Ede, Nigeria. \\ Sinmiat Abiodun Oladapo \\ Food Science and Technology Department, \\ P.M.B. 301, Osun State Polytechnic, Iree, Nigeria.
}

\begin{abstract}
The study examined the sugar types and sum sugars in selected brands of commercial fruit juice. The sugar types were determined base on the reducing properties of the monosaccharide sugars using Lane and Eynon method. Non-reducing sugar was estimated after it hydrolysis. The data obtained were subjected to statistical analysis using ANOVA and Hierarchical Clustering (Dendrogram). The results showed that there is no significant difference in the sugar content amongst the seven brands of fruit juice analyzed. However, the results indicated that there is significant difference in the sugar types (Dextrose, Fructose and Sucrose) found in the samples. Fructose was found to be the higher concentrated of the two reducing sugars determined (Dextrose and Fructose) across the samples analyzed. Sample $B$ has the highest fructose and dextrose concentrations $(5.22 \pm 0.02 \mathrm{~g} / 100 \mathrm{~mL})$ and $(4.92 \pm 0.01$ $\mathrm{g} / 100 \mathrm{~mL}$ ) respectively while $\mathrm{G}$ has the lowest concentrations of the two sugars $(4.76 \pm 0.01 \mathrm{~g} / 100 \mathrm{~mL})$ and $(4.49 \pm 0.01 \mathrm{~g} / 100 \mathrm{~mL})$. Maximum sucrose content was recorded in $G(9.36 \pm 0.02 \mathrm{~g} / 100 \mathrm{~mL})$ out of 18.61 $\mathrm{g} / 100 \mathrm{~mL}$ total sugar reported for the sample. Lowest sucrose was observed in sample $E(6.96 \pm 0.03 \mathrm{~g} / 100 \mathrm{~mL})$ out of $16.33 \mathrm{~g} / 100 \mathrm{~mL}$ total sugar. There is significant amount of sucrose in all the fruit juice sample analyzed.
\end{abstract}

Keywords:- Fruit Juice, Sugars, Sucrose, Titrimetric Method.

\section{INTRODUCTION}

Fruits of all types contain many components that are beneficial to healthy well being of man. It is this realization that made dieticians to emphasis the importance of fruits as components of balanced diets. However some fruit contain substantial amount of liquid and thus, the liquid components can be extracted as juice. The extracted juice from fruits can be commercially processed, preserved and packed in attractive manner thus, making it portable and potable. The commercial brands of fruit juice contain an abundance of vitamins, minerals, anti- oxidants and fibers which are essential in human diet [1].
However, these brands of commercial fruit juice may contain high quantities of sugars (mainly natural) which may not be healthy when taken in high quantities. Too much sugar could be harmful to health of the consumers. It could result to diabetes, obesity, heart disease, and other complications as a result of excessive consumption of fruit juice [2]. It is widely acknowledged that junk food is bad and fruit and vegetables are good. However, researches have established that excessive consumption of fruit juices may be detrimental to health $[3,4,5,6]$.

The most abundant natural sugar in fruit is fructose, also known as fruit sugar. It is a simple monosaccharide absorbed directly into the bloodstream during digestion [7]. Fructose is present in fruits, vegetables, and honey. It was erroneously believed that fructose is healthier than sucrose because it is found naturally in fruit. However, it can be equally harmful and bad as sugar cane (sucrose) [6]. Sucrose is a compound of one molecule of glucose and one molecule of fructose [7] and is commonly referred to as table sugar [6]. The increasing occurrence of obesity, diabetes mellitus, and non-alcoholic fatty liver disease could be the result of excessive fructose intake as well [7].

It has been reported that fruit juice is not the same as intact fruit and it has been reported to contain as much sugar as many classical sugar drinks. Study has also revealed that fruit juice sugars also absorbed very fast as soon as it get into the stomach irrespective of the source [1]. Fructose may promote the formation of toxic advanced glycation-end products, which may contribute to diabetes, the aging process, and the thickening of artery walls [8].

Fruit in its natural state, contains fructose together with essential vitamins, minerals and fibre and therefore, it is regarded as balanced diet. However, extracted fruit juice cannot be regarded as balanced diet. In natural state, sugar (fructose) is stored in the cells of fruit and stays mostly within the cell walls of fruit. It is only released and broken down when it reaches the digestive system on consumption. Therefore, it is released slowly into the bodies and the fruit fibres help to slow down it digestion [7]. 
However, in fruit drink (juice), the fructose in the cells is free and may act directly on teeth causing decay. It also enters directly into the bloodstream causing a spike in the blood sugar which can lead to weight gain and other health issues, just like regular sugar (sucrose) [8].

There is concern about excessive sugar consumption amongst the populace and it attendance health consequences and it is therefore important to determine the amount of sugar and sugar types in commercial fruit juice samples thought to be natural and hence devoid of the health implications. The chemical method (Lane and Eynon) was adopted for the determination of sugars in the commercial fruit juice samples obtained from markets in Osun state of Nigeria.

\section{MATERIALS AND METHODS}

\section{A. Sampling Procedure of Fruit Juice.}

A total of 7 brands of fruit juice samples of three different batches at each trial were purchased from different markets in Osun state between June and August. 2019. Therefore, a total of 21 samples were analyzed in the laboratory in triplicate trials.

The experimental methodology entailed the use of chemical (Lane and Eynon) method. Non-reducing sugars are first converted into reducing sugars by hydrolysis for estimation. The method is based on the principle of reduction of Fehling's solution by reducing sugars. Fehling's solutions: a mixture of copper sulphate and alkaline sodium potassium tartarate. The tartarate salt complexes with the cupric hydroxide formed in alkaline solution which prevents it from precipitation and the reducing sugars reduce the complexed cupric hydroxide to red, insoluble cuprous oxide under the experimental conditions. An oxidation-reduction indicator (methylene blue) detects the end point of the titration [9].

\section{B. Standardization of Sucrose Solution}

Diluted invert sugar standard solution (10\%) was prepared and the $\mathrm{pH}$ was adjusted to 8.0 using $\mathrm{NaOH}$ solution. It was titrated with $5.0 \mathrm{~mL}$ of boiling mixture each of Fehling A and Fehling B solutions with three drops of $1 \%$ methylene blue as indicator until the blue color of the indicator disappeared to a brick red end point. The titration was completed within 3 minutes and blank titration was performed without hydrolyzing sucrose sample [10]. The titration was performed in triplicates and the average titre value was obtained.

\section{Determination of Initial Reducing Sugar Content is Samples}

The fruit juice sample $(5 \mathrm{ml})$ was accurately measured and diluted to 50 folds. The $\mathrm{pH}$ of the diluted sample was adjusted to $\mathrm{pH} 8$ using $\mathrm{NaOH}$ solution and titrated against boiling mixture of Fehling $\mathrm{A}$ and $\mathrm{B}$ solution as performed for the sucrose standardization in $B$ above.
D. Hydrolysis of the Fruit Juice Sample and Analysis of Total Sugar Content

The fruit juice sample $(5 \mathrm{~mL})$ was mixed with $3 \mathrm{~mL}$ of conc. $\mathrm{HCl}$ and kept at $70^{\circ} \mathrm{C}$ for 30 minutes. The $\mathrm{pH}$ of the mixture was adjusted to 8 with $\mathrm{NaOH}$ solution and 50 times diluted. The hydrolyzed sample solution was transferred into a burette and titrated against boiling mixture of Fehling solution A \& B as before.

\section{E. Determination of Sucrose Content in Fruit Juice Samples}

Total reducing sugar content of initial fruit juice sample was quantified by titration. The total reducing sugar content of the hydrolyzed fruit juice sample was quantified in the same manner. Then, the total reducing sugar content of the hydrolyzed fruit juice sample and reducing sugar content of original fruit juice sample were subtracted and the value was taken as \%w/w.

This value was multiplied by 0.95 . Sucrose content of the sample was obtained through this calculation as \%w/w. These non reducing sugars are usually expressed in terms of sucrose and $1 \mathrm{~g}$ sucrose on hydrolysis yields $0.95 \mathrm{~g}$ invert sugar (glucose + fructose). Factor 0.95 was used for the calculation.

\section{Sucrose in the sample $(\% \mathrm{w} / \mathrm{w})=$}

[Total reducing sugars $(\% \mathrm{w} / \mathrm{w})$ - Initial reducing sugars $(\%$ w/w)] X 0.95.

\section{F. Method Validation and Quality Control}

The tested samples were spiked with the known volume of invert sugar standard solution in triplicate and the titration was carried out as above and the final results were recorded. Furthermore, the triplicate samples were spiked with the known amount of sucrose and the titration was carried out and results were recorded.

\section{G. Calculations}

\section{Dextrose Sugar:}

Sample volume diluted to a known volume Hence, dilution Factor $(\mathrm{DF})=\frac{\text { Final Volume }}{\text { Initial Volume }}$ Total volume $(500 \mathrm{ml})$

Titre value $\longrightarrow$ Dextrose value from the Table Total volume $(500 \mathrm{ml}) \longrightarrow X$

$$
\mathrm{X}=\frac{\text { Total volume } \mathrm{x} \text { Dextrose }(\text { Table) value }}{\text { Titre value }}
$$

Percentage Dextrose $(\%)=\frac{\mathrm{x}}{1000 \times 20} \times 100$

\section{Fructose Sugar:}

Sample volume diluted to a known volume Hence, dilution Factor $(\mathrm{DF})=\frac{\text { Final Volume }}{\text { Initial Volume }}$ Total volume $(500 \mathrm{ml})$

Titre value $\longrightarrow$ Fructose (Table) value

Total volume $(500 \mathrm{ml}) \longrightarrow \mathrm{Y}$

$$
\mathrm{Y}=\frac{\text { Total volume } \mathrm{x} \text { Dextrose }(\text { Table) value }}{\text { Titre value }}
$$




\section{Invert Sugar:}

$20 \mathrm{ml}$ sample diluted to $100 \mathrm{ml}$,

$\mathrm{DF}=5$

Total volume $=250 \mathrm{ml} \times \mathrm{DF}=1250 \mathrm{ml}$

Titre value $\longrightarrow$ Dextrose (Table) value

Total volume $\longrightarrow \mathrm{Z}$

$$
\mathrm{Z}=\frac{\text { Total volume } \mathrm{x} \text { Dextrose (Table) value }}{\text { Titre value }}
$$

\section{Sucrose Sugar}

\section{Invert Sugar - Red가cing sugar x 0.95}

The factor 0.95 was derived from the assumption that simple sugar contains $95 \%$ sucrose.

\section{RESULTS AND DISCUSSION}

The results of sugar determination were subjected to a univariate ANOVA based on a comparison of means indicated. There was significant difference amongst the sugar types (dextrose, fructose and sucrose) contents in all commercial bottled fruit juice samples $(\mathrm{P}<0.05)$. The difference in the sugar types noticed amongst the analyzed samples could be as a result of the fact that the samples are prepared from different fruit sample and by different manufactures [13, 14,]. However, there was no significant difference observed amongst all the seven samples analyzed $(p>0.05)$. There is no significant difference between the reducing sugars amongst the samples (fig.1).

The maximum concentration of dextrose (a reducing sugar) was found in sample B $(4.92 \pm 0.01 \mathrm{~g} / 100 \mathrm{~mL})$ while the minimum concentration was found in sample $\mathrm{G}(4.49 \pm$ $0.01 \mathrm{~g} / 100 \mathrm{~mL})$. The highest concentration of fructose (another reducing sugar) was found in sample B $(5.22 \pm 0.02$ $\mathrm{g} / 100 \mathrm{~mL}$ ) while the lowest concentration of this sugar type was found in sample $\mathrm{G}(4.76 \pm 0.01 \mathrm{~g} / 100 \mathrm{~mL})$.

The maximum sucrose content was observed in $\mathrm{G}$ and the value was $9.36 \pm 0.02 \mathrm{~g} / 100 \mathrm{~mL}$ out of $18.61 \mathrm{~g} / 100 \mathrm{~mL}$ total sugar reported for the sample. The lowest sucrose content was observed in sample E

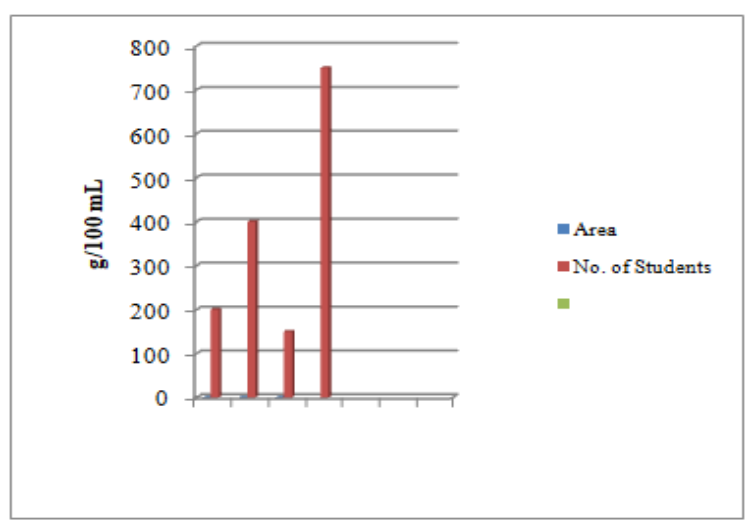

Fig 1:- Composition of Sugar Types Compositions of Fruit Juice Samples

The value was $6.96 \pm 0.03 \mathrm{~g} / 100 \mathrm{~mL}$ out of $16.33 \mathrm{~g} / 100$ $\mathrm{mL}$ total sugar $[2,11,12,13]$
Overall, of all seven fruit juice samples with "no sugar added" claim, Sample G arose curiosity. This is because this sample has the lowest concentrations of the reducing sugars (dextrose and fructose). There is possibility that the sample has been fortified with sucrose (a non reducing sugar commonly used as sweetener in food formulations) and this may be the reason for it having the largest concentration of sucrose [7].

Sweetness is one of the main attributes of fruit juice and as such, the results of the analysis established that all the fruits juices samples under investigation are sweet almost to the same degree and cannot be differentiated on the basis sweetness. No significant difference was observed between dextrose and fructose $(p>0.05)$ in all samples. There was significant difference between sucrose found in all the samples fig. 2 and their reducing sugars (dextrose and fructose) [15, 16, 17, 18, 19].

Using hierarchical clustering (Dendrogram) fig.3, the similarity amongst the fruit juice samples in term of their sugar contents can be explained [20]. There is a close

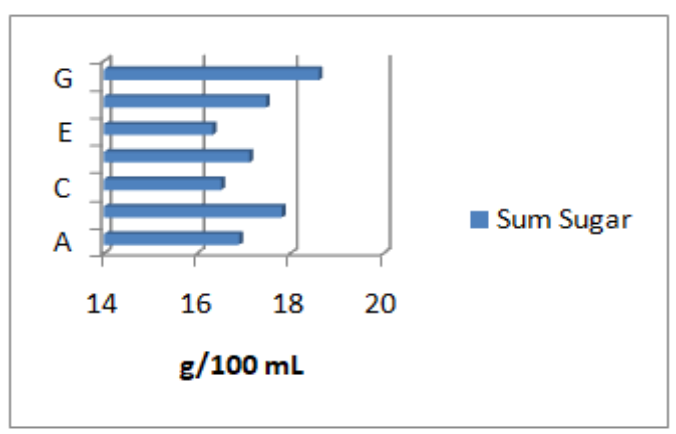

Fig 2:- Sum Sugar Compositions of the Fruit juice Samples

Similarity between A and D and C and E. Samples B and $F$ are also similar but at greater distance than the first set $(\mathrm{AD}$ and $\mathrm{CE}$ ). There is a noticeable similarity between FB cluster and ADCE clusters though, at higher distance [20]. Sample G is far distant from other samples as shown in the dendrogram (fig. 3). The similarities noticed amongst the samples are attributable to the concentrations of dextrose and fructose in the samples. The dissimilarity of sample $G$ from others could be ascribed to its sucrose concentration.

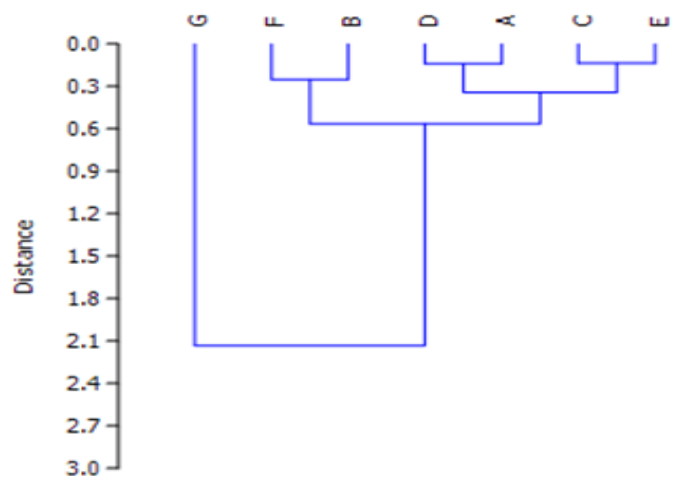

Fig 3:- Hierarchical Clustering (Dendrogram) Amongst Fruit Juice Samples 


\section{CONCLUSIONS}

This paper presents an experimental study on the comparison of sugar content between commercial packed fruit juices that are sold in the marketplaces in Osun State using Lane and Eynon method. Statistical analysis of the experimental results indicated that there was no significant difference in the sugar concentrations between the two reducing sugars (dextrose and fructose) in all tested fruit juice samples. However, sucrose, a non-reducing sugar commonly used as sweetener in food formulations is found to be the principal component sugar in the entire samples. It should therefore be of concern that sucrose, a sugar type that has been implicated as the cause of health problems in both adults and children is substantially present in the commercial brands of fruit juice. However, it is important to recognize the limitations of this study. The validity of the results could have been affected by the samples' origin and surrounding climate among other possible factors.

\section{REFERENCES}

[1]. J. Y Serpen. "Comparison of sugar content in bottled $100 \%$ fruit juice versus extracted juice of fresh fruit". Food and Nutrition Sciences, 2012.3,1509-1513. Doi/10.4236/fns.2012.311196

[2]. S. D. C.Sewwandi, P. C. Arampath, A. B. G.Silva and Jayatissa R.." Determination and comparative study of sugars and synthetic colorants in commercial branded fruit juice products" Journal of Food Quality vol. 2020, p11 https://doi.org/10.1155/2020/7406506.

[3]. WHO. "Calls on countries to reduce sugars intake among adults and children". https://www.who.int/mediacentre/ news/releases/2015/sugar-guideline/en/.

[4]. J. Rippe and T Angelopoulos." Relationship between added sugars consumption and chronic disease risk factors: current understanding". Nutrients 2016, 8(11): 697.

[5]. C. E. O’Neil, T. A Nicklas. M. Zanovec, and I. L Fulgoni, "Diet quality is positively associated with 100 $\%$ fruit juice consumption in children and adults in the United States". Nutrition Journal, 2011, 10(1): 17- 26. doi:10.1186/1475-2891-10-17

[6]. A. Pepin, K. L. Stanhope and P. Imbeault. "Are fruit juices healthier than sugar-sweetened beverages?". A review. Nutrients 2019, .11:1006. doi:10.3390/nu11051006

[7]. J.S. White, L.J Hobbs and S. Fernandez, "Fructose content and composition of commercial HFCSsweetened carbonated beverages. International Journal of Obesity.2014, 39:176-182.

[8]. A. Guilbaud, C. Niquet-Leridon, E. Boulanger and F.J Tessier. "How can diet affect the accumulation of advanced glycation end-products in the human body"? A review. Foods.2016, 5, 84; doi:10.3390/foods5040084
[9]. AOAC. "Invert sugar in sugars and syrups, Lane and Eynon general volumetric method (Method 923.09) Official Methods of Analysis of Association of Official Analytical Chemists (2000).15th edition, Better World Books, Reno, NV, USA.

[10]. JCAM. "Quantitative analysis of reducing sugars in sugar preparations consisting of sugar and dextrin. Japan Customs Analysis Methods. 2001, (No.114-R1) 1-6.

[11]. A.Fateh, T Ines, and F. Ali. "HPLC determination of sugars and atomic absorption analysis of mineral salts in fresh figs of Tunisian cultivars". Journal of Biotechnology. 2007,6(5):599-602.

[12]. T. I. Edewor-Kuponiyi. "Determination of fructose content in Anacardium occidentale. International Journal of Agricultural and Food Research. 2013, 2(3): 13-19.

[13]. L. C. Anyika, S. I. Okonkwo and E. N. Ejike "Comparative analysis of monosaccharide and disaccharide using different instrument refractometer and polarimeter". International Journal of Research in Chemistry and Environment. 2012, 2(4): 270-274.

[14]. S. Chandraju, R. Mythily and C. S. Chidan Kumar.'Extraction,isolation and identification of sugars from banana peels (Musa sapientum) by HPLC coupled LC/MS instrument and TLC analysis". Journal of Chemical and Pharmaceutical Research. 2011, 3(3): 312-321.

[15]. F. Shen, Y.Ying, B. Li, Y. Zheng and J. Hu "Prediction of sugars and acids in Chinese rice wine by mid-infrared spectroscopy". Food Research International. 2011, 44(5): 1521-1527.

[16]. M. Jurkova, C. Pavel, K. Sterba and J. Olsovka. "Determination of total carbohydrate content in beer using its pre-column enzymatic cleavage and HPLCRI'. Food Analytical Methods. 2014, 7(8): 1677-1686.

[17]. A. Sapcanin, G. Jancan and R. Jadric. "Determination of sugar content in flavored waters". Bulletin of Chemical Technology of Bosnia and Herzegovina. 2013, 41: 29-32.

[18]. D. Ayalew, S. Temesgen, M. Redi-Abshiro, B.S. Chandravanshi and E. Ele "Improvement in analytical methods for determination of sugars in fermented alcoholic beverages" Journal of analytical methods in chemistry, 2018. https://doi.org/10.1155/2018/4010298.

[19]. M.R. Alam, M.A. Habib, P. Chowdhury L.C. Shill and A. Al Mamum Md "Determination of ascorbic acid concentration in commercially available fruit drinks in Bangladesh". Asina Food Science Journal. 2019.13(3):1-6. https://doi.org/10.9734/afs/2019/v13i330112

[20]. G. Gan, C. Ma, J. Wu "Data Clustering: Theory, Algorithms and Applications", SIAM, 2007 https://tutorials-data-mining.blogspot.fr/ 